\title{
Correction to: Human Stem Cell Models of SARS-CoV-2 Infection in the Cardiovascular System
}

\author{
Kyle Ernzen ${ }^{1,2,3} \cdot$ Aaron J. Trask ${ }^{1,2,4} \cdot$ Mark E. Peeples $^{4,5} \cdot$ Vidu Garg $^{1,2,3,4} \cdot$ Ming-Tao Zhao $^{1,2,3,4,6}$ (D) \\ Published online: 22 October 2021 \\ @ Springer Science+Business Media, LLC, part of Springer Nature 2021
}

\section{Correction to: Stem Cell Reviews and Reports https://doi.org/10.1007/s12015-021-10229-4}

A non-intentional human error occurred in Fig. 1b for which authors apologize. The correct version of Fig. 1 including corrected panel $\mathrm{b}$ is provided below.

\section{a Structure of SARS-CoV-2}

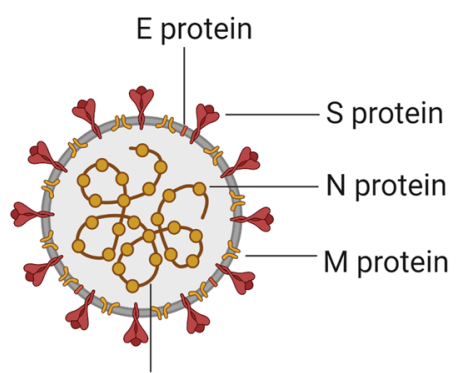

RNA viral genome

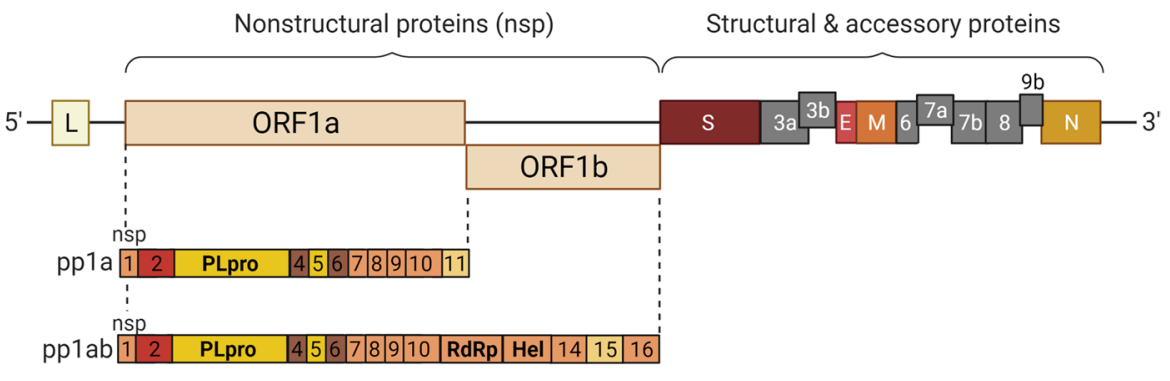

Publisher's Note Springer Nature remains neutral with regard to jurisdictional claims in published maps and institutional affiliations.

The original article can be found online at https://doi.org/10.1007/ s12015-021-10229-4.

Ming-Tao Zhao

Mingtao.Zhao@nationwidechildrens.org

1 Center for Cardiovascular Research, The Abigail Wexner Research Institute, Nationwide Children's Hospital, Columbus, OH, USA

b Genome of SARS-CoV-2

The Heart Center, Nationwide Children's Hospital, Columbus, $\mathrm{OH}$, USA

4 Department of Pediatrics, The Ohio State University College of Medicine, Columbus, OH, USA

5 Center for Vaccine and Immunity, The Abigail Wexner Research Institute, Nationwide Children's Hospital, Columbus, OH, USA

6 Department of Physiology and Cell Biology, The Ohio State University College of Medicine, Columbus, OH, USA 